\title{
Dental students' knowledge of medication-related osteonecrosis of the jaw
}

\author{
Daniele Rosella ${ }^{1}$, Piero Papi ${ }^{1}$, Giorgio Pompa ${ }^{1}$, Mario Capogreco ${ }^{2}$, \\ Francesca De Angelis ${ }^{1}$, Stefano Di Carlo ${ }^{1}$
}

Correspondence: Dr. Daniele Rosella

Email: daniele.rosella@gmail.com

\author{
'Department of Oral and Maxillo-Facial Sciences, \\ "Sapienza" University of Rome, Roma, Italy, \\ ${ }^{2}$ Department of Life, Health and Environmental \\ Sciences, University of L'Aquila, L'Aquila, Italy
}

\section{ABSTRACT}

Objectives: The aim of this study was to evaluate and assess knowledge and attitude of dental students about medication-related osteonecrosis of the jaw (MRONJ), to optimize future training programs in this field. Materials and Methods: A cross-sectional study was administrated. Ninety-eight participants agreed to complete an anonymous questionnaire. It was divided into two sections: the first section was about general information such as interviewer's gender and date of birth; the second section included questions about bisphosphonates (BPs), others medication associated to osteonecrosis of the jaw (ONJ), risk factors, and prevention of osteonecrosis. Descriptive statistics were computed and the odds ratio was used to compare the odds for the groups. Results: Ninety-nine percent of participants declared to know BPs, but only $26.9 \%$ of $4^{\text {th }}$ year and $34.8 \%$ of $6^{\text {th }}$ year students knew the correct definition of MRONJ. Almost all of students identified the importance to report, in anamnesis, the use of BPs, as well as to check-up patients before the beginning of treatment; on the other hand, the knowledge about how invasive dental treatment might be carried out in patients under therapy was not adequate. In addition, half of the students did not recognize any active principle or commercial name of BPs. The situation was even worse regarding alternative drugs involved in ONJ. Conclusions: These findings are alarming and the lack of knowledge about MRONJ suggests that greater educational efforts should be performed about this pathology at undergraduate level.

Key words: Bisphosphonate-related osteonecrosis of the jaw, bisphosphonates, medication-related osteonecrosis of the jaw, oral pathology, osteonecrosis, patient Safety/Medical Errors, preventive dentistry, undergraduate dental

\section{INTRODUCTION}

Medication-related osteonecrosis of the jaw (MRONJ) is an intense negative drug response, consisting of an increasing bone demolition in the maxillofacial area of patients. In 2014, the American Association of Oral and Maxillofacial Surgeons (AAOMS) proposed to replace the terminology from bisphosphonate-related osteonecrosis of the jaw (BRONJ) to MRONJ to include the improving amount of osteonecrosis of the jaws (ONJs) related with other antiresorptive

\begin{tabular}{|l|l|}
\hline \multicolumn{2}{|c|}{ Access this article online } \\
\hline Quick Response Code: \\
\hline
\end{tabular}

(denosumab) and antiangiogenetic therapies. ${ }^{[1,2]}$ Intravenous (IV) bisphosphonates (BPs) are used in the treatment of cancer-related conditions as well as skeletal-related events associated with bone metastases, hypercalcemia of malignancy, and for the management of lytic lesion in the setting of multiple myeloma. ${ }^{[3-5]}$ Oral BPs are used to manage condition including osteoporosis, ${ }^{[6]}$ osteopenia, ${ }^{[7]}$ osteogenesis imperfecta, ${ }^{[8]}$ and Paget's disease. ${ }^{\left[{ }^{[0]}\right.}$ RANK ligand

This is an open access article distributed under the terms of the Creative Commons Attribution-NonCommercial-ShareAlike 3.0 License, which allows others to remix, tweak, and build upon the work non-commercially, as long as the author is credited and the new creations are licensed under the identical terms.

For reprints contact: reprints@medknow.com

How to cite this article: Rosella D, Papi P, Pompa G, Capogreco M, De Angelis F, Di Carlo S. Dental students' knowledge of medicationrelated osteonecrosis of the jaw. Eur J Dent 2017;11:461-8.

DOI: 10.4103/ejd.ejd_27_17 
inhibitor (denosumab) is an antiresorptive drug, which arrests the function of osteoclasts, reduces bone resorption, and intensifies bone density. ${ }^{[10,11]}$ Antiangiogenetic medications inhibit the development of new blood vessels by stopping the angiogenesis signaling cascade. They are mostly divided into monoclonal antibodies, which block the receptor or growth factor (bevacizumab), and small molecules, which obtain the stop by binding the tyrosine kinase receptor (sunitinib and sorafenib). Several authors have been suggested that they may help other anticancer agents' delivery. Oral checkups and adequate therapy are essential to decrease the risk of ONJ in patients currently treated with antiresorptive or antiangiogenetic drugs or before initiating the administration. ${ }^{[12-16]}$ Treatment of ONJs is an important challenge for clinicians, and the right treatment protocol of MRONJ is still yet to be decided. Therefore, prevention is essential. There is a very low risk of ONJ related to oral BPs $(0.04 \%-0.1 \%)$, but it increments when the duration of treatment is superior to 4 years. ${ }^{[17]}$ This period decreases in case of chronic corticosteroid drugs assumption. ${ }^{[16,18]}$ In case of drug use for $<4$ years without risk factors, no alteration or postponement of surgery is needed, and all dental treatment are possible. ${ }^{[1]}$ If the therapy exceed 4 years or in case of risk factors, an antibiotic prophylaxis for oral surgery procedures is necessary, ${ }^{[19]}$ and conservative treatment should be preferred to dentoalveolar surgery. The risk of MRONJ increases in cancer patients $(0.2 \%-6.7 \%)$. Before to start an intravenous therapy, the patient should be referred to a dentist to treat any unstable oral situation, preventing the need for invasive dental procedures in the near or intermediate future. ${ }^{[20]}$ Surgical treatment should be avoided during the therapy; if necessary, extraction of teeth should be completed with the minimum bone injury, providing a primary wound closure and antibiotic prophylaxis. If allowed by the patient systemic condition, a drug holiday should be considered until the healing of soft tissue has occurred.

Despite the abundance of research papers about BRONJ in the past decade, just a few authors ${ }^{[21,22]}$ have investigated the level of information and knowledge among dental students (DSs), and according to the authors' knowledge, no study at all is focusing on MRONJ. The aim of this study was to evaluate the knowledge and attitude of Italian DSs about MRONJ, to optimize the future training programs in this important field.

\section{MATERIALS AND METHODS}

\section{Study design}

A cross-sectional study was administrated at "Sapienza" University of Rome (Italy) in September 2015.

\section{Materials and/or subjects}

Students volunteered for the study responding to an E-mail sent to the beginning classes of $4^{\text {th }}$ year (shortly after the oral pathology examination) and $6^{\text {th }}$ year (last and mostly clinical year of course). A total of 98 participants, 52 DSs of the $4^{\text {th }}$ year of course (DS4) and 46 DS6, agreed to participate in the survey. An anonymous questionnaire [Figure 1] was divided into two parts, and by agreeing to answer it, participants signed informed consent. The first section was about general information such as interviewer's gender and date of birth. The second section included questions about BPs, others medication associated with ONJ, risk factors, and prevention of jaws osteonecrosis. In addition, there were questions regarding how they learned about BPs and if they were interested in learning more about MRONJ. A single interviewer administrated the questionnaire, and consultation of any data source was not allowed while taking the test. Questions had a different evaluation system. there were questions with only items "YES" / NO" / "Don't know/no answer" and questions where subjects had to indicate commercial names/indications or definitions of drugs and MRONJ. To evaluate the results, items were classified as correct/no correct and answer "don't know/no answer" was classified as incorrect.

\section{Statistical analysis}

A specific statistical software (IBMSPSS V10 Statistics, IBM, Armonk, USA) was used to analyze data. Descriptive statistics were computed and the odds ratio was used to compare the odds for the two groups.

\section{RESULTS}

A total sample of 98 participants, 44 males (44.9\%) and 54 females $(55.1 \%)$, with a mean age of 24.1 years (ranging from 21 to 29 years) participated to the survey. Ninety-five students (96.9\%) declared that they first heard about BPs at University, two of them $(2.0 \%)$ reading scientific papers, and one $(1.0 \%)$ never heard about BPs. However, only $14(26.9 \%)$ DS4 and 16 (34.8\%) DS6 knew the correct definition of MRONJ as made by AAOMS. ${ }^{[1]}$ Most of DSs knew the principal 


$$
\begin{aligned}
& \text { Age } \\
& \text { Sex } \\
& \text { Year of Course }
\end{aligned}
$$

1. Do you know bisphosphonate drugs?
a. Yes
b. No

2. Where have you heard about Bisphosphonates for the first time?
a. Never heard
b. University
c. Mass media
d. Scientific Journals
e. Medical meetings
f. Other (motivate the answer)

3. Do you think it is important to ask if patients are using bisphosphonates?
a. Yes
b. No
c. I don't know

4. What are the pathologies target of a Bisphosphonates therapy? (it is possible to mark more than one choice)
a. bone metastases
b. osteomyelitis
c. multiple myeloma
d. hypercalcemia of malignancy
e. osteopetrosis
f. osteopenia and osteoporosis
g. chondroblastoma
h. osteogenesis imperfecta
i. paget's diseas of bone

5. Mark the active principle and commercial name of the Bisphosphonates you know:
a. No one
b. Alendronate (Fosamax)
c. Risendronate (Actonel)
d. Ibandronate (Boniva)
e. Neridronate (Nerixia)
f. Pamidronate (Aredia)
g. Zolendronate (Zometa)
h. Tiludronate (Skelid)

6. Do you know that Bisphosphonates can lead to Osteonecrosis of the jaw?
a. yes
b. no

Figure 1: English translation of the questionnaire administered to Italian dental students: Page 1 
7. What is the correct definition of osteonecrosis of the jaw according to the American Association of Oral and Maxillofacial Surgeons (AAOMS)?

a. Exposed bone or bone that can be probed through an intraoral or estraoral fistula(e) in the maxillofacial region wich has persisted for more than 8 weeks in patients in current or previous therapy with antiresorptive or antiangiogenetic agents and no history of radiaton therapy to the jaws or obvious metastatic disease to the jaws

b. Exposed bone or bone that can be probed through an intraoral or estraoral fistula(e) in the maxillofacial region wich has persisted for more than 4 weeks in patients in current or previous therapy with antiresorptive or antiangiogenetic agents and no history of radiaton therapy to the jaws or obvious metastatic disease to the jaws

c. Exposed bone or bone that can be probed through an intraoral or estraoral fistula(e) in the maxillofacial region wich has persisted for more than 8 weeks in patients in current or previous therapy with antiresorptive or antiangiogenetic agents and amedical history of radiaton therapy to the jaws or obvious metastatic disease to the jaws

d. Exposed bone or bone that can be probed through an intraoral or estraoral fistula(e) in the maxillofacial region wich has persisted for more than 4 weeks in patients in current or previous therapy with antiresorptive or antiangiogenetic agents and a medical history of radiaton therapy to the jaws or obvious metastatic disease to the jaws

e. I don't know

8. Which are the risk factors related to osteonecrosis of the jaw? (it is possible to mark more than one choice)

a. tobacco

b. antibiotic therapy

c. way of administration

d. alcohol

e. arterial hypertension

f. lenght of therapy

g. molecule

h. hyperlipidemia

i. steroid therapy

j. total amount

k. microtrauma

9. Do you think patients should be checked by the dentist before to start a IV bisphosphonates treatment?
a. yes
b. no
c. I don't know

10. Can invasive dental treatments be given to patients during an intravenous bisphosphonate drug therapy?
a. yes
b. no
c. I don't know

11. Can invasive dental treatments be given to patients using oral bisphosphonates for $<4 \mathrm{yrs}$ without risk factors?
a. yes
b. no
c. I don't know

Figure 1: English translation of the questionnaire administered to Italian dental students: Page 2 
12. Can invasive dental treatments be given to patients using oral bisphosphonates for $<4$ yrs with risk factors?
a. yes
b. no
c. I don't know

13. Can invasive dental treatments be given to patients using oral bisphosphonates for $>4$ yrs?
a. yes
b. no
c. I don't know

14. Do you know any other medication involved in the osteonecrosis of the jaw? (mark the drug you know)
a. I don't know any non-Bisphosphonates drug involved in the osteonecrosis of the jaw
b. Denosumab (Xgeva, Prolia)
c. Sunitib (Sutent)
d. Sorafenib (Nexavar)
e. Bevacizumab (Avastin)
f. Sirolimus (Rapamune)

15. Would you like to learn more about the osteonecrosis of the jaw?
a. yes
b. no
c. I don't know

Figure 1: English translation of the questionnaire administered to Italian dental students: Page 3

pathologies target of a BP treatment. Osteopenia and osteoporosis were recognized by $94.2 \%$ of DS4 and $97.8 \%$ of DS6; bone metastases by $65.4 \%$ of DS4 and $71.7 \%$ DS6. Diseases occurring less frequently were not recognized as well as the above-mentioned pathologies [Table 1]. Data about knowledge of risk factors involved in the ONJ are also presented in Table 1. Zoledronate (Zometa) was the best-recognized BP drug: 34 (65.4\%) DS4, 36 (78.3\%) DS6; denosumab (Xgeva, Prolia) was the best known no-BP drug: 14 (26.9\%) DS4 and 15 (32.6\%) DS6 [Table 2]. Almost all of DS, 92 (93.9\%) identified the importance to report in anamnesis the use of BPs as well as to check-up patients before the beginning of BP administration (80 [81.6\%]); on the other hand, the knowledge about how invasive dental treatment may be carried out in patients under BP drug administration was not adequate [Table 3]. About the question "Would you like to learn more about MRONJ?," 42 (80.8\%) DS4 and $40(87.0 \%)$ DS6 replied to be interested in increasing their knowledge about MRONJ.

\section{DISCUSSION}

To decrease the incidence as well as to provide a better treatment of ONJ events, a high level of knowledge about MRONJ should be obtained. Since the first case description of BRONJ in 2003, hundreds of studies have been reported all over the world, and several scientific societies have published guidelines about this subject. . $^{[1,2,12,23,24]}$ However, only two studies ${ }^{[17,18]}$ examined the current degree of awareness of DS about BRONJs, with neither one focusing on knowledge of other drugs related to ONJ.

Despite nearly all the participants, 51 DS4 (98.1\%) and 46 DS6 (100\%), declared their knowledge of BPs and the possible risk of ONJ, only $14(26.9 \%)$ of DS4 and $16(34.8 \%)$ of DS6 knew the right definition of MRONJ. In addition, half of the participants did not recognize any active principle or commercial name of BPs. The situation was even worse regarding the alternative drug involved in ONJ. Denosumab and its most common commercial names Xgeva 
Rosella, et al.: Dental students' knowledge of MRONJ

\begin{tabular}{|c|c|c|c|c|c|}
\hline & Total $(n=98), n(\%)$ & DS4 ( $n=52), n(\%)$ & DS6 $(n=46)^{*}, n(\%)$ & OR & $95 \% \mathrm{Cl}$ \\
\hline \multicolumn{6}{|l|}{ Pathologies } \\
\hline Paget's disease of bone & $41(41.8)$ & $23(44.23)$ & $18(39.1)$ & 1.23 & $0.55-2.76$ \\
\hline Osteogenesis imperfect & $16(16.3)$ & $9(17.3)$ & $7(15.2)$ & 1.17 & $0.40-3.43$ \\
\hline Osteopenia and osteoporosis & $94(95.9)$ & $49(94.2)$ & $45(97.8)$ & 0.36 & $0.04-3.62$ \\
\hline Hypercalcemia of malignancy & $12(12.2)$ & $7(13.5)$ & $5(10.9)$ & 1.28 & $0.37-4.33$ \\
\hline Bone metastases & $67(68.4)$ & $34(65.4)$ & $33(71.7)$ & 0.74 & $0.31-1.76$ \\
\hline Multiple myeloma & $39(39.8)$ & $20(38.5)$ & $19(41.3)$ & 0.89 & $0.39-2.00$ \\
\hline \multicolumn{6}{|l|}{ Risk factors } \\
\hline Tobacco & $37(37.8)$ & $21(40.4)$ & $16(34.8)$ & 1.27 & $0.56-2.89$ \\
\hline Way of administration & $70(71.4)$ & $35(67.3)$ & $35(76.1)$ & 0.65 & $0.26-1.58$ \\
\hline Alcohol & $19(19.4)$ & $11(21.1)$ & $8(17.4)$ & 1.27 & $0.46-3.51$ \\
\hline Length of therapy & $78(79.6)$ & $39(75.0)$ & $39(84.8)$ & 0.54 & $0.19-1.50$ \\
\hline Molecule & $53(54.1)$ & $24(58.5)$ & $29(63.0)$ & 0.50 & $0.22-1.13$ \\
\hline Steroid therapy & $23(23.5)$ & $11(21.1)$ & $12(26.1)$ & 0.76 & $0.30-1.94$ \\
\hline Total amount & $70(71.4)$ & $36(69.2)$ & $34(73.9)$ & 0.79 & $0.33-1.92$ \\
\hline Microtrauma & $63(64.3)$ & $32(61.5)$ & $31(67.4)$ & 0.77 & $0.34-1.78$ \\
\hline
\end{tabular}

\begin{tabular}{|c|c|c|c|c|c|}
\hline & Total $(n=98)$ & DS4 ( $n=52)$ & DS6 $(n=46)^{*}$ & OR & $95 \% \mathrm{Cl}$ \\
\hline \multicolumn{6}{|c|}{ BPs active principle (commercial name) } \\
\hline Alendronate (Fosamax) & $59(60.2)$ & $29(55.8)$ & $30(65.2)$ & 0.67 & $0.30-1.52$ \\
\hline Risedronate (Actonel) & $13(13.3)$ & $6(11.5)$ & $7(15.2)$ & 0.73 & $0.23-2.34$ \\
\hline Ibandronate (Boniva) & $21(21.4)$ & $11(21.1)$ & $10(21.7)$ & 0.97 & $0.37-2.54$ \\
\hline Neridronate (Nerixia) & $3(3.1)$ & $2(3.8)$ & $1(2.2)$ & 1.80 & $0.16-20.53$ \\
\hline Pamidronate (Aredia) & $39(39.8)$ & $20(38.7)$ & $19(41.3)$ & 0.89 & $0.39-2.00$ \\
\hline Zoledronate (Zometa) & $70(71.4)$ & $34(65.4)$ & $36(78.3)$ & 0.52 & $0.21-1.30$ \\
\hline Tiludronate (Skelid) & $1(1.0)$ & 0 & $1(2.2)$ & - & - \\
\hline \multicolumn{6}{|c|}{ No-BPs active principle (commercial name) } \\
\hline Denosumab (Xgeva, Prolia) & $29(29.6)$ & $14(26.9)$ & $15(32.6)$ & 0.76 & $0.32-1.82$ \\
\hline Sunitinib (Sutent) & $23(23.5)$ & $11(21.1)$ & $12(26.1)$ & 0.76 & $0.30-1.94$ \\
\hline Sorafenib (Nexavar) & $3(3.1)$ & $2(3.8)$ & $1(2.2)$ & 1.80 & $0.16-20.53$ \\
\hline Bevacizumab (Avastin) & $24(24.5)$ & $12(23.1)$ & $12(26.1)$ & 0.85 & $0.34-2.14$ \\
\hline Sirolimus (Rapamune) & $1(1.0)$ & 0 & $1(2.2)$ & - & - \\
\hline
\end{tabular}

and Prolia were recognized by only $14(26.9 \%)$ DS4 and 15 (32.6\%) DS6; sunitinib (Sutent) and bevacizumab (Avastin) were identified by $16(23.5 \%)$ and $18(24.5 \%)$ DS, respectively. Only one $(1.0 \%)$ participant recognized sirolimus (Rapamune), while $2(3.8 \%)$ DS4 and 1 (2.2\%) DS6 identified sorafenib (Nexavar). The data above-mentioned showed a discrepancy between the high sensitivity to the issue and the real ability to recognize or prevent a medication-related osteonecrosis. Hence, patients during anamnesis usually answer to the question "What medications are you taking?" reporting the commercial name of the drug, much more rarely indicating the active principle. Obviously, they do not suggest to the doctor the class of medication they are receiving or the possible risk of developing $\mathrm{ONJ}$ during dental treatment. ${ }^{[25]}$

A total of $92(93.9 \%)$ DS affirmed to be aware of the importance to report in the medical record if patients are using or not BPs although they did not know how to behave toward patients needing a dental treatment. 39 (75.0\%) DS4 and $40(87.0 \%)$ DS6 know that they should not proceed with invasive dental treatments in patients under IV BPs administration. However, the management of patients who undertake oral BPs is more confused. Only 15 (28.8\%) DS4 and 18 (39.1\%) DS6 know how to approach patients taking oral BPs for $<4$ years without risk factors; 10 (19.2\%) DS4 and 13 (29.3\%) 


\begin{tabular}{|c|c|c|c|c|c|}
\hline Questions about dental treatments & Total $(n=98), n(\%)$ & DS4 ( $n=52), n(\%)$ & DS6 $(n=46)^{*}, n(\%)$ & OR & $95 \% \mathrm{Cl}$ \\
\hline Do you know BP drugs? & $97(99.0)$ & $51(98.1)$ & $46(100)$ & - & - \\
\hline $\begin{array}{l}\text { Do you think it is important to ask } \\
\text { if patients are using BPs? }\end{array}$ & $92(93.9)$ & $47(90.4)$ & $45(97.8)$ & 0.21 & $0.02-1.86$ \\
\hline $\begin{array}{l}\text { Do you think patients should be checked by the } \\
\text { dentist before to start an IV BPs treatment? }\end{array}$ & $80(81.6)$ & $36(69.2)$ & $44(95.6)$ & 0.10 & $0.02-0.47$ \\
\hline $\begin{array}{l}\text { Can invasive dental treatments be given to } \\
\text { patients during an IV BP drug therapy? }\end{array}$ & $79(80.6)$ & $39(75.0)$ & $40(87.0)$ & 0.45 & $0.16-1.30$ \\
\hline $\begin{array}{l}\text { Can invasive dental treatments be given to patients } \\
\text { using oral BPs for }<4 \text { years without risk factors? }\end{array}$ & $33(33.7)$ & $15(28.8)$ & $18(39.1)$ & 0.63 & $0.27-1.47$ \\
\hline $\begin{array}{l}\text { Can invasive dental treatments be given to patients } \\
\text { using oral BPs for }<4 \text { years with risk factors? }\end{array}$ & $23(23.5)$ & $10(19.2)$ & $13(28.3)$ & 0.60 & $0.24-1.55$ \\
\hline $\begin{array}{l}\text { Can invasive dental treatments be given to patients } \\
\text { using oral BPs for }>4 \text { years? }\end{array}$ & $53(54.1)$ & $27(51.9)$ & $26(56.5)$ & 0.83 & $0.37-1.84$ \\
\hline
\end{tabular}

DS6 are able to manage a patient under oral BPs administration for $<4$ years with risk factors. Almost half of participants (48.1\% DS4 and $43.5 \%$ DS6) are incompetent in treating a patient under oral BPs administration for over 4 years. An important information arises from the study: Participants even if they are capable of recognizing a person who is taking a BP and the possible risk of ONJ, they don't know how to provide a safe dental treatment for each group of patients.

The well-known indication of BPs is the treatment of osteoporosis (94.2\% DS4; 97.8\% DS6) followed by bone metastases (65.4\% DS4; 71.7\% DS6); this means that more than one out of three DSs are unable to recognize the group of patients which has the highest risk to develop an MRONJ, which is cancer patients. The situation regarding risk factors related to MRONJ is equally unsatisfactory. The best-known risk factors are the ones related to the drug. On the other hand, the most important data are probably that only $11(21.1 \%)$ DS4 and $12(26.1 \%)$ DS6 are aware of the importance of steroid therapy as a risk factor. In fact, the Position Paper of AAOMS ${ }^{[1]}$ underlines how corticosteroids are the main discriminating factor in patients who are taken oral BPs for $<4$ years.

The year of course may influence the answers to some questions. The authors expected DS4 interviewed just shortly after the examination of oral pathology, in which they had a lecture about the subject of the questionnaire, to obtain higher scores compared to DS6. In reality, DS6 showed a better knowledge, probably due to their more clinical experience. However, statistically, significant difference between the two groups was found just in one question (Do you think patients should be checked by the dentist before to start an IV BPs treatment?) while other dissimilarity might be due to chance.

The comparison between the present study and the results of previous works on the Spanish ${ }^{[21]}$ and Brazilian ${ }^{[22]}$ DSs showed a general better knowledge of the Italian DSs about BPs active principles and commercial names. For example, alendronate (Fosamax) was recognized by $38 \%$ of Spanish DS and $60 \%$ of Italian DS; zoledronate (Zometa) was identified by $32 \%$ Spanish DS and 71\% Italian DS. The majority of Brazilian DS (75\%) did not know the $\mathrm{BP}$ cited in the questionnaire, and their commercial names were not recognized by $86 \%$ of them. On the other hand, the Spanish students appeared to have a better knowledge about the risk factors related to ONJ. For instance, the chronic corticosteroid therapy was identified as a risk factor by $80 \%$ of Spanish DS as compared to $24 \%$ of Italian DS. They also showed a greater awareness about the management of patients who are going to start or under therapy with medication related to ONJ.

Anyway data are alarming and the lack of information about MRONJ suggests that greater educational efforts should be performed about this pathology at undergraduate level.

\section{CONCLUSIONS}

A better level of knowledge by DS may lead, in future, to minimize incidence of MRONJ as well as to a better resolution of ONJ cases. ${ }^{[22]}$ This might be important not only clinically but also on the legal side. A trained group of dental professionals diminish the possibility of legal cost and damages. 
According to our findings, theoretical and practical initiatives should be promoted to improve and consolidate the knowledge of future dental practitioners about this important issue; however, further studies, possibly with a multicenter design, with larger samples and different evaluation methods are necessary.

\section{Financial support and sponsorship Nil.}

\section{Conflicts of interest}

There are no conflicts of interest.

\section{REFERENCES}

1. Ruggiero SL, Dodson TB, Fantasia J, Goodday R, Aghaloo T, Mehrotra B, et al. American Association of Oral and Maxillofacial Surgeons position paper on medication-related osteonecrosis of the jaw-2014 update. J Oral Maxillofac Surg 2014;72:1938-56.

2. Ruggiero SL, Dodson TB, Assael LA, Landesberg R, Marx RE, Mehrotra B; American Association of Oral and Maxillofacial Surgeons. American Association of Oral and Maxillofacial Surgeons position paper on bisphosphonate-related osteonecrosis of the jaws--2009 update. J Oral Maxillofac Surg 2009;67 5 Suppl: 2-12.

3. Aapro M, Abrahamsson PA, Body JJ, Coleman RE, Colomer R, Costa L, et al. Guidance on the use of bisphosphonates in solid tumours: Recommendations of an international expert panel. Ann Oncol 2008;19:420-32.

4. Mallik S, Mallik G, Macabulos ST, Dorigo A. Malignancy associated hypercalcaemia-responsiveness to IV bisphosphonates and prognosis in a palliative population. Support Care Cancer 2016;24:1771-7.

5. Van den Wyngaert T, Delforge M, Doyen C, Duck L, Wouters K, Delabaye I, et al. Prospective observational study of treatment pattern, effectiveness and safety of zoledronic acid therapy beyond 24 months in patients with multiple myeloma or bone metastases from solid tumors. Support Care Cancer 2013;21:3483-90.

6. McClung MR, Balske A, Burgio DE, Wenderoth D, Recker RR. Treatment of postmenopausal osteoporosis with delayed-release risedronate $35 \mathrm{mg}$ weekly for 2 years. Osteoporos Int 2013;24:301-10.

7. Chapurlat RD, Laroche M, Thomas T, Rouanet S, Delmas PD, de Vernejoul MC. Effect of oral monthly ibandronate on bone microarchitecture in women with osteopenia-a randomized placebo-controlled trial. Osteoporos Int 2013;24:311-20.

8. Bishop N, Adami S, Ahmed SF, Antón J, Arundel P, Burren CP, et al. Risedronate in children with osteogenesis imperfecta: A randomised, double-blind, placebo-controlled trial. Lancet 2013;382:1424-32.

9. Yoh K, Takata S, Yoshimura N, Hashimoto J. Efficacy, tolerability, and safety of risedronate in Japanese patients with Paget's disease of bone. J Bone Miner Metab 2010;28:468-76.

10. Delmas PD. Clinical potential of RANKL inhibition for the management of postmenopausal osteoporosis and other metabolic bone diseases. J Clin Densitom 2008;11:325-38.

11. Fizazi K, Carducci M, Smith M, Damião R, Brown J, Karsh L, et al. Denosumab versus zoledronic acid for treatment of bone metastases in men with castration-resistant prostate cancer: A randomised, double-blind study. Lancet 2011;377:813-22.

12. Rosella D, Papi P, Giardino R, Cicalini E, Piccoli L, Pompa G. Medication-related osteonecrosis of the jaw: Clinical and practical guidelines. J Int Soc Prev Community Dent 2016;6:97-104.

13. Dimopoulos MA, Kastritis E, Bamia C, Melakopoulos I, Gika D, Roussou M, et al. Reduction of osteonecrosis of the jaw (ONJ) after implementation of preventive measures in patients with multiple myeloma treated with zoledronic acid. Ann Oncol 2009;20:117-20.

14. Ripamonti CI, Maniezzo M, Campa T, Fagnoni E, Brunelli C, Saibene G, et al. Decreased occurrence of osteonecrosis of the jaw after implementation of dental preventive measures in solid tumour patients with bone metastases treated with bisphosphonates. The experience of the National Cancer Institute of Milan. Ann Oncol 2009;20:137-45.

15. Pompa G, Bignozzi I, Cristalli MP, Quaranta A, Di Carlo S. Bisphosphonates and Osteonecrosis of the jaw: The oral surgeon's perspective. Eur J Inflamm 2012;101:11-23.

16. Saad F, Brown JE, Van Poznak C, Ibrahim T, Stemmer SM, Stopeck AT, et al. Incidence, risk factors, and outcomes of osteonecrosis of the jaw: Integrated analysis from three blinded active-controlled phase III trials in cancer patients with bone metastases. Ann Oncol 2012;23:1341-7

17. Lo JC, O'Ryan FS, Gordon NP, Yang J, Hui RL, Martin D, et al. Prevalence of osteonecrosis of the jaw in patients with oral bisphosphonate exposure. J Oral Maxillofac Surg 2010;68:243-53.

18. Vandone AM, Donadio M, Mozzati M, Ardine M, Polimeni MA, Beatrice $S$, et al. Impact of dental care in the prevention of bisphosphonate-associated osteonecrosis of the jaw: A single-center clinical experience. Ann Oncol 2012;23:193-200.

19. Marx RE, Sawatari Y, Fortin M, Broumand V. Bisphosphonate-induced exposed bone (osteonecrosis/osteopetrosis) of the jaws: Risk factors, recognition, prevention, and treatment. J Oral Maxillofac Surg 2005;63:1567-75.

20. Hellstein JW, Adler RA, Edwards B, Jacobsen PL, Kalmar JR, Koka S, et al. Managing the care of patients receiving antiresorptive therapy for prevention and treatment of osteoporosis: Executive summary of recommendations from the American Dental Association Council on Scientific Affairs. J Am Dent Assoc 2011;142:1243-51.

21. López-Jornet P, Camacho-Alonso F, Molina-Miñano F, Gomez-Garcia F. Bisphosphonate-associated osteonecrosis of the jaw. Knowledge and attitudes of dentists and dental students: A preliminary study. J Eval Clin Pract 2010;16:878-82.

22. de Lima PB, Brasil VL, de Castro JF, de Moraes Ramos-Perez FM, Alves FA, dos Anjos Pontual ML, et al. Knowledge and attitudes of Brazilian dental students and dentists regarding bisphosphonate-related osteonecrosis of the jaw. Support Care Cancer 2015;23:3421-6.

23. Kim KM, Rhee Y, Kwon YD, Kwon TG, Lee JK, Kim DY. Medication related osteonecrosis of the jaw: 2015 Position Statement of the Korean Society for Bone and Mineral Research and the Korean Association of Oral and Maxillofacial Surgeons. J Bone Metab 2015;22:151-65.

24. Japanese Allied Committee on Osteonecrosis of the Jaw, Yoneda T, Hagino H, Sugimoto T, Ohta H, Takahashi S, et al. Antiresorptive agent-related osteonecrosis of the jaw: Position Paper 2017 of the Japanese Allied Committee on Osteonecrosis of the Jaw. J Bone Miner Metab 2017;35:6-19.

25. Monwell B, Blix O, Gerdner A, Bülow P. Drug list as a cognitive support to provide detailed information on a patient's drug use: A comparison of two methods within the assessment of drug misuse and dependence. Subst Use Misuse 2016;51:1470-6. 